\title{
The Actual Operative Costs of Liver Transplantation and Normothermic Machine Perfusion in a Canadian Setting
}

\author{
Alexandria N. Webb ${ }^{1}$ (D) Dayne L. Izquierdo ${ }^{2} \cdot$ Dean T. Eurich $^{3}$ (D) A. M. James Shapiro ${ }^{1,2} \cdot$ David L. Bigam $^{1}$ (D)
}

Accepted: 30 October 2020 / Published online: 15 November 2020

(c) The Author(s) 2020

\begin{abstract}
Background Liver transplantation is an effective treatment for end-stage liver disease. However, waiting lists continue to lengthen as demand exceeds supply. Use of extended criteria donors has helped but is associated with increased rates of complications. The application of normothermic machine perfusion (NMP) has been shown to be protective, especially in more marginal grafts. Despite this benefit, no cost-effectiveness studies have been published.

Objective This study serves as a prelude to a cost-effectiveness analysis of the costs of liver procurement, transplantation, and machine perfusion in a Canadian setting.

Methods The total costs were calculated for 106 in-province procurements, the set cost for 237 out-of-province procurements, and 343 liver transplantations. These costs include overheads, supplies, anaesthesia technologist and nursing salaries, and physician billings. Base and modified costs for all procedures were calculated, with consideration of physician billing modifiers. The total cost per run of NMP was calculated, with a range based on variations in the exchange rates for Great British pounds (£) to Canadian dollars (\$Can), year 2019 values.

Results Costs were $\$$ Can30,770.22 for in-province and \$Can44,636.73 for out-of-province liver procurement and transplantation. These increased to $\$$ Can35,659.22 and 48,076.18 when considering modifiers. The minimum cost per NMP run was $\$ C a n 18,593.02$.

Conclusions Although the cost per run is substantial, NMP could potentially lead to cost savings by decreasing night-time salary premiums, complications, and patient length of stay. A formal cost-effectiveness study of NMP in liver transplantation is underway to help clarify the financial benefit or burden of this new technology.
\end{abstract}

Electronic supplementary material The online version of this article (https://doi.org/10.1007/s41669-020-00241-8) contains supplementary material, which is available to authorized users.

Alexandria N. Webb

awebb1@ualberta.ca

1 Department of Surgery, University of Alberta, $8440112 \mathrm{St}$, Edmonton, AB T6G 2B7, Canada

2 Clinical Islet Transplant Program, University of Alberta, Edmonton, AB, Canada

3 School of Public Health, University of Alberta, Edmonton, $\mathrm{AB}$, Canada

\section{Key Points for Decision Makers}

This paper defined actual costs per run for normothermic machine perfusion used in liver transplantation from a Canadian single-payer perspective as well as the potential cost savings accrued through a transition from nighttime to daytime transplant surgery hours.

This paper provides insight into the actual costs for transplant surgery and the per run cost of normothermic machine perfusion. This is the prelude to a formal cost-effectiveness analysis to inform healthcare decisions based on the outcome of length of stay with the addition of machine perfusion to transplant programmes. 


\section{Introduction}

Liver transplantation remains the only life-saving treatment for many forms of liver disease; however, a mismatch between the supply and demand for liver transplants results in up to one-quarter of listed patients dying while on the waiting list [1]. The 2018 statistics from the Canadian Institute for Health Information stated that 507 adults were awaiting liver transplantation, where 358 were actively awaiting and 149 were on hold [2]. A total of 190 adults were removed from the waiting list: 80 had died and 110 withdrew due to improvement or deterioration of their condition, giving a waiting list death rate of $22 \%$ [2].

To address the gap between the supply and demand for liver transplants, the acceptance and transplantation of extended criteria donors (ECD) has increased. This has occurred in two waves [3]. The initial criteria expansion was for conventional factors such as age, abnormal liver function tests, liver steatosis, etc., and the second wave was for non-conventional factors such as hepatitis B- and $\mathrm{C}$-infected grafts and donation after cardiac death [3]. The use of ECD grafts is associated with an increased risk of early allograft dysfunction, biliary complications, and graft failure, with further risk when combined with the use of standard static cold storage (SCS), compared with the use of standard criteria donors (SCD) [4]. In an effort to improve post-transplant complications from ECDs, the development and use of machine perfusion has become a focal point of current research.

OrganOx Ltd is a Europe-based company that has created a machine called metra for normothermic machine perfusion (NMP) [5]. The use of NMP allows for physiologic numbers to be maintained, including temperature, oxygenation, and blood flow and pressure [5]. Variables including bile output, lactate clearance, glucose metabolism, transaminase levels, and blood gas analysis allow transplant surgeons to assess the liver's metabolic and synthetic functioning ex vivo before exposing a recipient to the graft [5]. In 2016, the first clinical trial of the OrganOx metra machine proved safety and feasibility [6]. In 2018, Nasralla et al. [7] published the first randomised controlled trial (RCT) of machine perfusion with the OrganOx metra device. Both of these studies showed a statistically significant improvement in peak aspartate aminotransferase (AST) level and lower rates of early allograft dysfunction [6, 7]. This led to a further large multicentre RCT in the USA that is awaiting completion, with the primary outcome of measuring early allograft dysfunction $[5,8]$. In Canada, two clinical trials with the OrganOx machine are ongoing $[9,10]$, but no detailed cost analyses of the OrganOx machine have been published to date.

The American Society of Transplant Surgeons' standards committee is expecting that the addition of machine perfusion will add $\$ U S 25,000-50,000$ to the overall cost of one liver transplant [11]. Although there have been estimations of the added financial burden from machine perfusion, no data have been released to show an expected actual cost. The purpose of this study is to show the actual operating room costs associated with liver procurement, liver transplantation, and machine perfusion using the OrganOx machine in a Canadian setting.

\section{Methods}

The cost analysis was prompted by the liver transplant team at the University of Alberta (UofA) Hospital and conducted from the Canadian single-payer perspective. All costs are based out of the UofA Hospital in Edmonton, AB, Canada, and presented in Canadian dollars (\$Can), year 2019 values. This cost analysis considers overheads, supplies, and staffing for the operative costs of liver procurement, transplant, and OrganOx metra. The costs presented in this study are actual costs as opposed to standard costs. The total calculated costs are based on the costs that the UofA Hospital and Alberta Health Services - the provincial health authoritypay for overheads, supplies, and salaries. This is compared with setting a standard total cost for the procedure and all components.

\subsection{Liver Procurement and Transplant}

\subsubsection{Overhead and Supply Costs}

The average case costs, including salaries and supplies, were collected from the LightHouse Surgical Financial System for the multivisceral organ procurement and liver transplantation operations. LightHouse is a financial monitoring system used by the UofA operating room to track the actual costs of operative cases [12]. The UofA Hospital is the only hospital in the province of Alberta that completes liver transplantations, so all liver transplant operative costs are captured in the LightHouse data. LightHouse collects the actual cost data directly from the UofA Hospital using their electronic tracking systems for each operation to account for the overhead costs of the operating room, supply costs from the case, and nursing salaries [12]. Using the cost data, the average cost for a specific operation can be compared between individual surgeons and an average cost based on all surgeons who complete that operation [12]. In this cost analysis, the average case cost is the average based on all liver transplant surgeons at the UofA Hospital, which represents the actual case cost based on the actual operative costs used by the UofA Hospital. All costs were collected from April 2015 to July 2019 for 106 in-province multivisceral organ procurement and liver transplantations. The Hospital Reciprocal 
Claims Guide provided the set cost for 237 out-of-province organ procurements [13].

The Human Organ Procurement and Exchange (HOPE) programme provides additional operative supplies specific for liver procurement (Table S1 in the electronic supplementary material [ESM]). The HOPE programme is a subdivision of Northern Alberta Transplant Services through Alberta Health Services [14]. The HOPE programme coordinates the process of deceased organ donation, overseeing the details of donation, allocation, recovery, and distribution [14]. These supply costs were added to the average case costs.

\subsubsection{Staff}

The surgeon and anaesthesiologist billing costs were collected from the regional Health Service Codes Fee Navigator for donor total hepatectomy, recipient total hepatectomy, and liver transplantation [15]. The billing costs were calculated for each operation and range from the base pay without modifiers to the base pay with maximum modification. Modification is applied to both the surgeon and the anaesthesia billing for a body mass index (BMI) $>40$ and for timing of the operation, based on evening (1700-2200 h), night evening (2200-2400 h), and night morning (2400-0700 h) (Table S2 in the ESM) [15]. The nursing salaries are part of the average case costs collected from LightHouse.

\subsubsection{Total Cost}

The total cost of in-province procurement is made up of the average case cost, HOPE supplies, surgeon billing, and anaesthesia billing. The total cost of out-of-province procurement is made up of the Alberta Reciprocal Claim and HOPE supplies. The recipient total hepatectomy and liver transplant cost is made up of the average case cost, surgeon billing, and anaesthesia billing.

\subsection{OrganOx Machine Perfusion}

\subsubsection{Overhead and Supplies}

The average case costs for the OrganOx machine, run by anaesthesia technicians, were collected through LightHouse for April 2017 to July 2019. The average case cost is the cumulative cost of overheads for the operating room, operative supplies, and nursing salaries. The UofA Hospital provided the costs of the materials they supply (Table S3 in the ESM). OrganOx Ltd provided the costs of the OrganOx machine annual lease and supplies, based on the contractual agreement between OrganOx and UofA of completing a minimum of 15 OrganOx runs per year, in Great British pounds (£), year 2019 values (Table S4 in the ESM). The minimum of 15 runs per year was an initial agreement to the volume to be utilised with potential for decreasing costs with increased utilisation. The costs were converted from $\$$ to \$Can, year 2019 values, based on the exchange rate range between 30 August 2018 and 30 August 2019. The conversion rate ranged from 1.5955 to 1.7743 [16]

\subsubsection{Staff}

The average case cost from LightHouse covers the salaries of the nurses who set up the operating room and are present until the liver is attached and running on the OrganOx machine. Once the machine is running, an anaesthesia technician monitors the liver until it is taken off the machine for transplantation. The average hours of liver perfusion were collected for all completed OrganOx perfusions. The salary of an anaesthesia technician is $\$ C$ an $40-50 / \mathrm{h}$, depending on seniority; when called in overnight, pay is double time at $\$ C$ an80-100/h [17]. The average salary for the anaesthesia technician was calculated from the average number of hours based on overtime for runs during night-time hours (1900-0700 h) and base pay for runs during daytime hours (0700-1900 h).

\subsubsection{Total Cost}

The cumulative OrganOx run cost was calculated with the average case cost, hospital supply costs, OrganOx supply costs, and anaesthesia technician salary. The cumulative costs of liver procurement, liver transplantation, and OrganOx perfusion were calculated for both in-province and out-of-province procurement and transplantation. The costs of standard transplant and transplant with OrganOx were compared using a t-test, with a p-value of 0.05 considered statistically significant.

\section{Results}

\subsection{Liver Procurement and Transplant}

The cost of a liver transplant from an operative perspective involves staffing salaries and supply costs for multivisceral organ procurement of the donor, recipient total hepatectomy, and recipient liver transplantation. Multivisceral organ procurement occurs outside of the regional hospital two-thirds of the time. Therefore, additional travel costs need to be included.

The multivisceral organ procurement case costs from LightHouse provided the average case cost, made up of supplies and salaries. The average case cost from the last 5 years was \$Can9537.20 \pm standard deviation (SD) 753.13 (Table 1). This was broken down to an average supply cost 
Table 1 Multivisceral organ procurement case costs

\begin{tabular}{llcllcc}
\hline Costs & $\begin{array}{l}2019 / 2020 \\
(n=5)\end{array}$ & $\begin{array}{l}2018 / 2019 \\
(n=19)\end{array}$ & $\begin{array}{l}2017 / 2018 \\
(n=33)\end{array}$ & $\begin{array}{l}2016 / 2017 \\
(n=25)\end{array}$ & $\begin{array}{l}2015 / 2016 \\
(n=24)\end{array}$ & Average \pm SD \\
\hline Average salaries & 1248 & 2154 & 1930 & 2422 & 2503 & $2051.40 \pm 502.99$ \\
Average supplies & 7558 & 8338 & 7333 & 6530 & 7669 & $7485.60 \pm 652.29$ \\
Average case cost & 8806 & 10,493 & 9263 & 8952 & 10,172 & $9537.20 \pm 753.13$ \\
\hline
\end{tabular}

Costs are presented in Canadian dollars, year 2019 values

$S D$ standard deviation
Table 2 Total operative costs for in-province procurement and transplantation

\begin{tabular}{ll}
\hline Procedure and costs & Costs \\
\hline Donor total hepatectomy & \\
Average case cost & $9537.20 \pm 753.13$ \\
HOPE supplies & 1077.85 \\
Surgeon & $2857.70-3854.49$ \\
Anaesthesia & $681.59-1134.35$ \\
Total & $14,154.34-15,603.89$ \\
Recipient total hepatectomy and liver transplantation \\
Average case cost & $6246.40 \pm 497.52$ \\
Surgeon & $7395.15-9808.66$ \\
Anaesthesia & $2974.33-4000.27$ \\
Total & $16,615.88-20,055.33$ \\
Cumulative total & $30,770.22-35,659.22$ \\
\hline
\end{tabular}

Costs are presented as range or average \pm standard deviation in Canadian dollars, year 2019 values

HOPE Human Organ Procurement and Exchange programme

of $\$$ Can7485.60 \pm 652.29 and an average salary cost of $\$$ Can2051.40 \pm 502.99 . The salary cost did not include the payments for which the surgeon and the anaesthesiologist bill. The surgeon's base pay for a donor total hepatectomy is $\$$ Can2857.70. The base pay for the anaesthesiologist is $\$$ Can681.59. In addition to the base pay, modifiers apply for BMI and for the time of day at which the operation is completed, which apply to both the surgeon and the anaesthesiologist. Therefore, surgeon billings range from \$Can2857.70 (base pay) to 3854.49 , and anaesthesiologist billings range from \$Can681.59 to 1134.35 . The average supplies did not include the supplies that are provided by the HOPE programme, which total \$Can1077.85. This yields a total cost of in-province procurement of \$Can14,154.34-15,603.89 (Table 2).

The average costs for liver transplantation obtained from LightHouse incorporate the case costs of the recipient total hepatectomy and deceased donor liver transplant. The average case cost from the last 5 years was \$Can6246.40 \pm 497.52 (Table 3). This was broken down to an average supply cost of \$Can2913.40 \pm 355.34 and an average salary cost of $\$$ Can3362.40 \pm 210.43 . The surgeon billings were separated by recipient total hepatectomy and liver transplantation. The surgeon base pay for recipient total hepatectomy is \$Can2377.01. Once modifiers were considered, the range was \$Can2377.01-3253.62. The surgeon base pay for liver transplantation is \$Can5018.14-6555.04 with modifiers. In total, the surgeon billing cost for both procedures ranged from \$Can7395.15 to 9808.66. The anaesthesiologist billing for liver transplantation was \$Can2974.33-4000.27 with modifiers. The total operative cost for the combination of recipient total hepatectomy and liver transplantation ranged from $\$ C$ an 16,615.88 to 20,055.33 (Table 2). In total, the operative cost of in-province procurement and transplantation was $\$$ Can30,770.22-35,659.33 (Table 2).

At times, procurement occurs at a distant site, so additional travel costs must be considered. Currently, the billing cost for out-of-province liver procurement is \$Can26,943, as per the Hospital Reciprocal Claims [13]. This is an allinclusive set cost for travel, supplies, salaries, and operating room costs and, with the addition of the HOPE supplies, the total cost for out-of-province procurement is $\$ \mathrm{Can} 28,020.85$ (Table 4). In total, the cost of a liver transplant with an outof-province procurement is \$Can44,636.73-48,076.18 (Table 4). Additional travel costs were considered for procurements occurring at a nearby regional hospital (\$Can190) or in a different city within the same province (\$Can5175).
Table 3 Liver transplantation case costs

\begin{tabular}{lllllll}
\hline Costs & $\begin{array}{l}2019 / 2020 \\
(n=23)\end{array}$ & $\begin{array}{l}2018 / 2019 \\
(n=73)\end{array}$ & $\begin{array}{l}2017 / 2018 \\
(n=97)\end{array}$ & $\begin{array}{l}2016 / 2017 \\
(n=80)\end{array}$ & $\begin{array}{l}2015 / 2016 \\
(n=70)\end{array}$ & Average \pm SD \\
\hline Average salaries & 3412 & 3102 & 3195 & 3612 & 3491 & $3362.40 \pm 210.43$ \\
Average supplies & 3478 & 2565 & 2660 & 2932 & 2932 & $2913.40 \pm 355.34$ \\
Average case cost & 6889 & 5668 & 5855 & 6544 & 6276 & $6246.40 \pm 497.52$ \\
\hline
\end{tabular}

Costs are presented in Canadian dollars, year 2019 values 
Table 4 Total operative costs for out-of-province procurement and inprovince transplantation

\begin{tabular}{ll}
\hline Procurement and transplantation & Costs \\
\hline Out-of-province donor total hepatectomy & \\
Alberta reciprocal claim & 26,943 \\
HOPE supplies & 1077.85 \\
Total & $28,020.85$ \\
Recipient total hepatectomy and liver transplantation \\
Average case cost & $6246.40 \pm 497.52$ \\
Surgeon & $7395.15-9808.66$ \\
Anaesthesia & $2974.33-4000.27$ \\
Total & $16,615.88-20,055.33$ \\
Cumulative total & $44,636.73-48,076.18$ \\
\hline
\end{tabular}

Costs are presented as range or average \pm standard deviation in Canadian dollars, year 2019 values

HOPE Human Organ Procurement and Exchange Program

\subsection{Organ0x Machine Perfusion}

For deceased donor liver grafts, OrganOx machine perfusion costs are in addition to the traditional liver transplantation costs. Current costs are made up of four distinct areas. The first is operating room costs (Table 5), which include the operating room nursing salaries and case supplies. This is an average of $\$ \operatorname{Can} 1667 \pm 192.57$. The second is the costs of medications and solutions purchased through the UofA Hospital, a total of \$Can1617.36.

The third is the cost of the annual lease of the OrganOx machine and the cassettes and solutions purchased from OrganOx Ltd. The costs of the lease and materials purchased from OrganOx Ltd were converted to \$Can, year 2019 values. The total cost of supplies per run for the OrganOx machine is $\$$ Can 14,708.66-16,356.99, based on the agreement between OrganOx and UofA for completion of a minimum of 15 OrganOx runs per year. The fourth is the salaries of the anaesthesia technicians. The OrganOx machine runs for an average of $9.08 \mathrm{~h}$, usually between 0300 and $1200 \mathrm{~h}$.

Table 5 OrganOx perfusion operating room case costs

\begin{tabular}{lllll}
\hline Costs & $\begin{array}{l}2019 / 2020 \\
(n=1)\end{array}$ & $\begin{array}{l}2018 / 2019 \\
(n=14)\end{array}$ & $\begin{array}{l}2017 / 2018 \\
(n=12)\end{array}$ & Average \\
\hline $\begin{array}{c}\text { Average } \\
\text { salaries }\end{array}$ & 1057 & 1393 & 1405 & $\$ 1285 \pm 197.54$ \\
$\begin{array}{c}\text { Average } \\
\text { supplies }\end{array}$ & 391 & 347 & 408 & $\$ 382 \pm 31.48$ \\
$\begin{array}{c}\text { Average } \\
\text { case cost }\end{array}$ & 1449 & 1740 & 1813 & $\$ 1667 \pm 192.57$ \\
\hline
\end{tabular}

Costs are presented as range or average \pm standard deviation in Canadian dollars, year 2019 values
Given this, the average additional costs for the anaesthesia technicians is \$Can600.

The cumulative operative cost for one run of OrganOx perfusion machine was $\$$ Can 18,593.02-20,241.35 (Table 6). Overall, the total cost of in-province procurement, liver transplant, and OrganOx was \$Can49,363.24-55,900.68. The total cost of out-of-province procurement, in-province transplantation, and OrganOx was \$Can63,229.75-68,317.53. The cost difference between liver transplant including OrganOx compared with standard liver transplant was statistically significant for both in-province $(\mathrm{p}=0.042)$ and outof-province $(p=0.024)$ transplant.

\section{Discussion}

Machine perfusion has been a core element of liver transplantation research for the last decade. The use of NMP for livers has been shown to have benefits for both the liver and the recipient. Nasralla et al. [7] published an RCT in 2018 that showed that peak AST, a marker of predicted graft and patient survival, was $49.4 \%$ lower in livers that underwent NMP. In addition, the odds of early allograft dysfunction was 74\% lower in the NMP livers, including both ECD and SCD grafts, than for SCS [7]. Post-reperfusion syndrome in NMP versus SCS was significantly reduced for recipients of NMP livers, and recipients also had a decreased requirement for vasopressors during the post-reperfusion period [7, 18]. It has also been shown that hepatic ischaemic reperfusion injury, using AST as a surrogate marker, is an independent risk factor for acute kidney injury post transplantation, which may require renal replacement with prolonged intensive care unit and hospital stays [19]. NMP has the potential to decrease this.

In addition to the potential clinical benefits of NMP, the surgical teams may also benefit. Traditionally, many transplantations occur during night-time hours [20]. Although studies have shown that patient outcomes are not impacted by night-time transplants, over time, the combination of night-time operating and a busy transplantation service can lead to transplant team burnout and potentially a lack of personnel available for call coverage [20-24]. The introduction of NMP has enabled a shift of transplantation from

Table 6 Total OrganOx case cost per run

\begin{tabular}{ll}
\hline Operative room average cost & $1667 \pm 192.57$ \\
Regional hospital supply cost & 1617.36 \\
OrganOx Ltd supply cost & $14,708.66-16,356.99$ \\
Anaesthesia technician cost & 600 \\
Cumulative total & $18,593.02-20,241.35$ \\
\hline
\end{tabular}

Costs are presented as range or average \pm standard deviation in Canadian dollars, year 2019 values 
night-time to daytime hours, as NMP can be run overnight $[7,25]$. However, successful NMP does require the transplant fellows at UofA to complete night-time operating to ensure final dissection and attachment of the liver graft to the OrganOx machine, which does play a role in fatigue specific to the fellows. Overall, 58 OrganOx liver transplants have been completed at UofA between 2015 and 2019, and $49(84.48 \%)$ of those switched from a potential nighttime (1900-0700 h) to a daytime $(0700-1900 \mathrm{~h})$ transplant because of the use of NMP. This is in comparison with $64 \%$ of SCS liver transplants being completed during daytime hours [25]. The shift to daytime transplantation will hopefully decrease the burnout that transplant services are being faced with.

In addition, shifting transplantation from night to day will impact costs via transplant team salaries. Daytime operations will remove the evening and night-time modifiers from the salaries of the surgeon and anaesthesiologist. In total, for the anaesthesiologist and the surgeon in recipient hepatectomy and liver transplantation, the total savings is $\$$ Can847.08. Currently, a transplantation that occurs overnight requires a transplant scrub nurse to be called in. That scrub nurse requires a minimum of $3 \mathrm{~h}$ of overtime pay at a rate of \$Can84-106/h depending on seniority; this is double time of the base pay with a shift differential of $\$ C$ an $5 / h$ [26]. However, the liver transplant cases range from 8 to $12 \mathrm{~h}$, with an additional $2-3 \mathrm{~h}$ of setup and clean up. Therefore, this yields a cost of \$Can252-1500 for the scrub nurse alone. If transplantation begins in the morning, this salary cost is eliminated. Therefore, the overall cost savings of salaries for transplantation may be up to \$Can2347.08 (4.86\% for in province, $3.71 \%$ for out of province). Although the salary cost savings are minimal, the potential exists for larger cost savings in the post-transplant time with fewer complications, investigations, and shorter length of stay, which will be considered in the future cost-effectiveness analysis (CEA) while considering the recipient's clinical status and Model for End-Stage Liver Disease score.

Use of the OrganOx machine also has the potential to increase the number of ECD accepted for perfusion and successful transplantation [7, 25]. This will lead to more liver transplants taking place and therefore decrease the waiting time for transplantation. This will ideally lead to fewer people dying on the wait list or becoming too sick to tolerate the stress of a transplant. If people receive their transplants earlier, this may also decrease the healthcare costs from the possible hospital stays and interventions that would have been required as their disease progressed. Overall, an increased number of usable livers will lead to more lives being saved and an increase in healthcare costs associated with liver transplantation. A further CEA will be completed to assess these concerns.
The area of cost has been considered, but no data have been published. The purpose of this study was to determine the actual operative costs of liver procurement, liver transplantation, and OrganOx machine perfusion. The cost of the OrganOx per run is substantial. Despite this, the clinical efficacy and considerations discussed with the use of the OrganOx may outweigh the costs given the possible decrease in investigations, complications, and length of stay post transplantation, which will be considered in the future CEA. In turn, this will lead to better quality of life and return to social functions for patients post transplantation. Overall, this may lead to a decreased cost to the medical system, and the future CEA will help clarify this by assessing length-ofstay outcomes.

This study has some limitations. First, these costs relate only to the operating room and not all the preoperative investigations and the hospital stay for the donor or the investigations, care management, hospital stays, clinic visits, and interventions completed for the recipient before their transplantation. The salaries for the managerial and nursing staff employed by the HOPE programme are also not included. Overall, these additional costs can be significant to the system but will likely be similar between the two groups. Costs related to post-operative care for the recipient are being collected for the CEA but are not currently considered; however, if the promising results from Nasralla et al. [7] are generalisable, we would expect the post-operative costs to be lower in the OrganOx group.

In addition, the costs are calculated within a Canadian setting, so the data may not be transferable to other countries with different protocols and billing setups for transplantation. In the Canadian setting, the costs of organ procurement and transplantation are covered in their entirety by the provincial organ donor programmes. Other countries have different payment models, including charge-based models, which may lead to different costs. In particular, it should be noted that all costs for organ procurement and transportation are covered separately through direct government funding across Canada, whereas in the USA, for example, these substantial costs with additional overheads are passed on to the recipient hospital and the recipient's insurance scheme. In the 2017-2018 fiscal year, the cost of one liver transplant admission in the region was \$Can102,597, excluding the physician costs. In comparison, in 2017, the estimate of charges for one liver transplant admission in the USA was \$US463,200, excluding physician costs [27].

In addition to these limitations, potential exists for the overall cost of liver transplant to increase substantially if the use of NMP allows for more livers to be useable and therefore available for transplantation, thereby leading to an increased number of lives saved. This study only shows the operative costs associated with organ procurement, transplantation, and NMP but does not account for the many 
additional costs incurred by the healthcare system for each individual transplant patient. While, clearly, incremental costs associated with the application of NMP are excluded from the current analysis, these costs become relatively much smaller if the total costs of donor and recipient transplant care, including transportation, are also included in the equation. As further research is conducted and the current clinical trials and RCTs completed, knowledge of the benefits of machine perfusion will be more extensive. This may lead to an increased use of machine perfusion. However, for healthcare systems to consider making additions to their protocols, the costs must be considered. This study of the costs of liver procurement, transplantation, and NMP is the prelude to a CEA of NMP.

\section{Conclusion}

The purpose of this study was to present the operative costs of liver transplantation and expected costs of OrganOx machine perfusion as a prelude to a CEA. The cost of liver transplant ranges from $\$$ Can30,770.22 to $35,659.22$ for inprovince and from $\$ C a n 44,636.73$ for $48,076.18$ for outof-province procedures. The cost of OrganOx per run is $\$$ Can 18,593.02-20,241.35. Although upfront costs are substantial, the possibility of NMP leading to a decreased length of stay and complications leads to a potential for cost savings in the Canadian system. In addition, the use of NMP usually shifts transplantation to daytime hours, thereby decreasing the premium night-time salaries. These potential cost savings may mean NMP is cost effective, and this question is currently undergoing formal CEA.

\section{Declarations}

Funding No sources of funding were used to conduct this study or prepare this manuscript.

Conflict of interest Alexandria N. Webb, Dayne L. Izquierdo, Dean T. Eurich, A.M. James Shapiro, and David L. Bigam have no conflicts of interest that are directly relevant to the content of this article.

Ethics approval Not applicable.

Consent to participate Not applicable.

Consent for publication Not applicable.

Data availability All data generated or analysed during this study are included in this published article [and its supplementary information files].

Code availability Not applicable.

Author contributions All authors contributed to the study conception and design. Material preparation, data collection and analysis were performed by ANW and DLI. The first draft of the manuscript was written by ANW and all authors commented on previous versions of the manuscript. All authors read and approved the final manuscript.

Open Access This article is licensed under a Creative Commons Attribution-NonCommercial 4.0 International License, which permits any non-commercial use, sharing, adaptation, distribution and reproduction in any medium or format, as long as you give appropriate credit to the original author(s) and the source, provide a link to the Creative Commons licence, and indicate if changes were made. The images or other third party material in this article are included in the article's Creative Commons licence, unless indicated otherwise in a credit line to the material. If material is not included in the article's Creative Commons licence and your intended use is not permitted by statutory regulation or exceeds the permitted use, you will need to obtain permission directly from the copyright holder. To view a copy of this licence, visit http://creativecommons.org/licenses/by-nc/4.0/.

\section{References}

1. Ascher N. Liver transplantation. In: Townsend CM, Beauchamp RD, Evers BM, Mattox KL, editors. Sabiston textbook of surgery: the biological basis of modern surgical practice. 20th ed. Philadelphia: Elsevier Saunders; 2017. p. 637-48.

2. Canadian Institute of Health Information. E-statistics on organ transplants, waiting lists and donors. 2019. https://www.cihi.ca/ en/e-statistics-on-organ-transplants-waiting-lists-and-donors. Accessed 30 Aug 2019.

3. Nemes B, Gámán G, Polak WG, et al. Extended criteria donors in liver transplantation part I: Reviewing the impact of determining factors. Expert Rev Gastroenterol Hepatol. 2016a;10(7):827-39.

4. Nemes B, Gámán G, Polak WG, et al. Extended-criteria donors in liver transplantation part II: reviewing the impact of extended-criteria donors on the complications and outcomes of liver transplantation. Expert Rev Gastroenterol Hepatol. 2016b;10(7):841-59.

5. OrganOx Ltd. Metra. 2019. https://www.organox.com/metra. Accessed 31 Aug 2019.

6. Ravikumar R, Jassem W, Mergental H, et al. Liver transplantation after ex vivo normothermic machine preservation: a phase 1 (firstin-man) clinical trial. Am J Transplant. 2016;16(6):1779-87.

7. Nasralla D, Coussios CC, Mergental H, et al. A randomized trial of normothermic preservation in liver transplantation. Nature. 2018;557(7703):50-6.

8. OrganOx Ltd. WPO1-normothermic liver preservation. 2019. https://clinicaltrials.gov/ct2/show/study/NCT0277516 2?term=normothermic+liver+perfusion. Accessed 5 Sep 2019.

9. University Health Network T. Using ex-vivo normothermic machine perfusion with the organox metra ${ }^{\mathrm{TM}}$ device to store human livers for transplantation. 2018. https://clinicaltrials.gov/ ct $2 /$ show/NCT02478151?cond=Using+Ex-vivo+Normotherm ic + Machine+Perfusion+With+the+Organox + Metra $^{\mathrm{TM}}+$ Devic $\mathrm{e}+$ to + Store + Human + Livers + for + Transplantation \& $r a n k=1$. Accessed 5 Sep 2019.

10. University of Alberta. Normothermic liver preservation trial. 2019. https://clinicaltrials.gov/ct2/show/NCT0308984 0 ? cond $=$ Normothermic + Liver + Preservation + Trial \&rank $=1$. Accessed 5 Sep 2019.

11. Quintini C, Martins PN, Shah S, et al. Implementing an innovated preservation technology: the American society of transplant surgeons' (ASTS) standards committee white paper on ex situ liver machine perfusion. Am J Transplant. 2018;18(8):1865-74.

12. Analysis Works. LightHouse. 2019. https://light-house.ca/. Accessed 18 Sep 2020. 
13. Alberta Health. Alberta health hospital reciprocal claims guide. Government of Alberta. 2019.

14. Alberta Health Services. Organ, tissue and eye donation. 2020. https://www.albertahealthservices.ca/services/Page13174.aspx. Accessed 18 Sep 2020.

15. Alberta Medical Association. Fee navigator. 2019. https://www. albertadoctors.org/fee-navigator. Accessed 30 Aug 2019.

16. Bank of Canada. Currency converter. 2019. https://www. bankofcanada.ca/rates/exchange/currency-converter/?looku pPage=lookup_currency_converter_2017.php\&startRange =2009-09-05\&rangeType $=$ range $\&$ select ToFrom $=$ from $\&$ conve $\mathrm{rt}=1.00 \&$ seriesTo $\% 5 \mathrm{~B} \% 5 \mathrm{D}=\mathrm{FXGBPCAD \& seriesFrom}=\mathrm{Canad}$ ian+dollar \&range Value $=\& d$ From $=2018-08-30 \& d T o=2019-08$ 30\&submit_button=Convert. Accessed 30 Aug 2019.

17. The Health Sciences Association of Alberta. Collective Agreement The Health Sciences Association of Alberta (Paramedical Professional and Technical Employees) and The Bethany Nursing Home of Camrose, AB, Lamont Health Care Centre, and Alberta Health Services. 2017. https://hsaa.ca/wp-content/uploa ds/2018/01/FINAL-AHS-HSAA-Collective-Agreement-April -1-2017-to-March-31-2020.pdf. Accessed 18 Sep 2020.

18. Angelico R, Perera MT, Ravikumar R, et al. Normothermic machine perfusion of deceased donor liver grafts is associated with improved postreperfusion hemodynamics. Transplant Direct. 2016;2(9):e97.

19. Leithead JA, Armstrong MJ, Corbett C, et al. Hepatic ischemia reperfusion injury is associated with acute kidney injury following donation after brain death liver transplantation. Transpl Int. 2013;26(11):1116-25.

20. Beckerid F, Voß T, Mohr A, et al. Impact of nighttime procedures on outcomes after liver transplantation. PLoS ONE. 2019. https:// doi.org/10.1371/journal.pone.0220124.

21. Balch CM, Shanafelt TD, Dyrbye L, et al. Surgeon distress as calibrated by hours worked and nights on call. J Am Coll Surg. 2010;211(5):609-19.

22. Shanafelt TD, Balch CM, Bechamps G, et al. Burnout and medical errors among American surgeons. Ann Surg. 2010;251(6):995-1000.

23. Balch CM, Shanafelt TD, Sloan JA, et al. Distress and career satisfaction among 14 surgical specialties, comparing academic and private practice settings. Ann Surg. 2011;254(6):558-68.

24. Orman ES, Hayashi PH, Dellon ES, et al. Impact of nighttime and weekend liver transplants on graft and patient outcomes. Liver Transpl. 2012;18(5):558-65.

25. Bral M, Dajani K, Leon Izquierdo D, et al. A back-to-base experience of human normothermic ex situ liver perfusion: does the chill kill? Liver Transplant. 2019;25:848-58.

26. The United Nurses of Alberta. Collective agreement between Alberta health services, covenant health, Lamont care centre, The Bethany Group (Camrose) and the United Nurses of Alberta. 2017. https://www.una.ab.ca/files/uploads/2018/11/Provincial _AHS_UNA_CA_2017-2020.pdf. Accessed 18 Sep 2020.

27. Bentley TS, Phillips SJ. 2017 US organ and tissue transplant cost estimates and discussion. Seattle: Milliman; 2017. 